\title{
Transformation of roxarsone by Enterobacter $s p$. CZ-1 isolated from an arsenic-contaminated paddy soil
}

\author{
K. Huang, F. Gao \& F.-J. Zhao \\ College of Resources and Environmental Sciences, \\ Nanjing Agricultural University, Nanjing, P.R. China
}

\begin{abstract}
Roxarsone $[\operatorname{Rox}(\mathrm{V})]$ is widely used as a feed additive in poultry industries. This arseniccontaining compound may be degraded by microbes to release toxic inorganic arsenic in the environment. To date, most of the studies of microbial mediated $\operatorname{Rox}(\mathrm{V})$ degradation have focused on anaerobic microorganisms. Here, we isolated a pure cultured aerobic $\operatorname{Rox}(\mathrm{V})$-degrading bacterial strain, CZ-1, from an arsenic-contaminated paddy soil in China. On the basis of 16S rRNA gene sequence, strain CZ-1 was classified as a member of genus Enterobacter. This strain could efficiently degrade Rox $(\mathrm{V})$, converting all of $10 \mu \mathrm{M} \operatorname{Rox}(\mathrm{V})$ within $24 \mathrm{~h}$ in liquid culture. Four metabolites including n-acetyl-4-hydroxy-m-arsanilic acid (N-AHPAA[V]), 3-amino-4-hydroxyphenylarsonic acid (3-AHPAA[V]), arsenite (As[III]) and an unknown arsenic compound were detected and identified by HPLC-ICP-MS and HPLC-LC-MS. N-AHPAA(V) was the main product, likely to be formed from acetylation of 3-AHPAA(V). Based on these results, a novel degradation pathway of Rox $(\mathrm{V})$ by Enterobacter. sp CZ-1 is proposed.
\end{abstract}

\section{INTRODUCTION}

The extensive use of the organoarsenical 3-nitro-4hydroxybenzene arsonic acid (roxarsone; Rox[V]) as a feed additive in the poultry industry can lead to increasing arsenic contamination of soil and water environments (Nachman et al., 2005; O'Conner et al., 2005). Previous studies using chicken feces and sewage sludge show that microbes play significant roles in degrading Rox $(\mathrm{V})$ in the environment (Cortinas et al., 2006; Stolz et al., 2007). Stolz et al. (2007) reported that Clostridium species were mainly responsible for $\operatorname{Rox}(\mathrm{V})$ degradation under anaerobic conditions in their enrichment cultures obtained from chicken litter. They also isolated an anaerobic Rox(V)degrading bacterium Clostridium OhILAs (Stolz et al., 2007). Two other anaerobic bacteria, Shewanella oneidensis MR-1 and Shewanella putrefaciens CN32, have also been found to possess the Rox(V) degradation ability (Chen et al., 2016; Han et al., 2017). Roxarsone biodegradation activity of an aerobic microbial consortium has also been demonstrated (GuzmanFierro et al., 2015), but to date no strains of aerobic microbes capable of $\operatorname{Ros}(\mathrm{V})$ degradation have been isolated. The degradation pathway under aerobic conditions remains unknown. In this study, we isolated and characterized an aerobic Rox(V)-degrading strain of Enterobacter, named CZ-1, and propose a novel biodegradation pathway.

\section{MATERIAL AND METHODS}

\subsection{Isolation and characterization of a Rox(V)-degrading bacterium}

One strain with a Rox(V)-degrading ability was isolated from an As-contaminated paddy soil and named CZ-1. Its ability for Rox $(\mathrm{V})$ degradation was determined quantitatively. The cell morphology was observed by SEM (S-3000N, Hitachi). The 16S rRNA gene was amplified by PCR and sequenced in Genscript Co. Ltd. The neighbor-joining phylogenetic tree was constructed by MEGA 5.0.

\subsection{Chemical analysis}

The metabolites produced in Rox $(\mathrm{V})$ degradation were analyzed by HPLC (series 200; PerkinElmer)-ICPMS (NexION 300D; PerkinElmer) using an anionexchange column (Hamilton PRP-X100; $250 \mathrm{~mm}$ by $4.6 \mathrm{~mm}$ ) eluted with the mobile phase [A: $50 \mathrm{mM}$ $\left(\mathrm{NH}_{4}\right)_{2} \mathrm{HPO}_{4}$; $\mathrm{B}$ : water] in gradient elution and LC-MS consisting of an Agilent 1200 series HPLC coupled to an Agilent 6410B triple quadrupole mass spectrometer using an Agilent Eclipse Plus C18 column $(2.1 \times 150 \mathrm{~mm}, 3.5 \mu \mathrm{m})$ with the mobile phase [95\% solution A ( $0.1 \%$ formic acid) and $5 \%$ solution $\mathrm{B}$ (acetonitrile)] at a flow rate of $0.2 \mathrm{~mL} \mathrm{~min}^{-1}$. 


\section{RESULTS AND DISCUSSION}

\subsection{Strain isolation and characterization}

One strain, designated strain CZ-1, capable of degrading $\operatorname{Rox}(\mathrm{V})$ was isolated from an arsenic-contaminated paddy soil in Chenzhou city, Hunan province, China. After $24 \mathrm{~h}$ of inoculation, strain CZ-1 was able to degrade all of $10 \mu \mathrm{M} \operatorname{Rox}(\mathrm{V})$ in ST10 $10^{-1}$ medium. Cells were Gram-negative, aerobic, and motile. A phylogenetic tree based on the 16S rRNA gene sequence of strain CZ-1 was constructed. Strain CZ-1 was closely related to Enterobacter sp. X72, with a sequence similarity score of $99 \%$, suggesting that strain CZ-1 is an Enterobacter species.

\subsection{Identification of the metabolites during $\operatorname{Rox}(V)$ degradation}

The products of the degradation of Rox $(\mathrm{V})$ by strain CZ-1 was first analyzed by HPLC-ICP-MS. The HPLC-ICP-MS analysis showed that nearly all of $\operatorname{Rox}(\mathrm{V})(10 \mu \mathrm{M})$ in the culture medium was converted to four As-containing metabolites designated compounds 1, 2, 3 and 4 . Compound 4 was found to be the main product. Compounds 1, 2 and 4 were preliminarily identified as As(III), 3-AHPAA(V) and NAHPAA(V), respectively, while compound 3 was still unknown that did not correspond to several common phenylarsine compounds such as 4-hydroxyphenylarsonic acid (HPAA[V]), 4-aminophenylarsonic acid (4APAA[V]), 2-aminophenylarsonic acid (2-APAA[V]) and carbarsone. When treated with $30 \% \mathrm{H}_{2} \mathrm{O}_{2}$, compound 1 was transformed to $\mathrm{As}(\mathrm{V})$, providing further evidence that compound 1 was As(III). In addition, the LC-MS analysis demonstrated the presence of 3$\operatorname{AHPAA}(\mathrm{V})$ and N-AHPAA$(\mathrm{V})$, confirming the results from the HPLC-ICP-MS analysis.

On the basis of above results, we propose a novel transformation pathway of Rox $(\mathrm{V})$ mediated by strain $\mathrm{CZ}-1$, which is different from the putative degradation pathways in Alkaliphilus oremlandii strain OhILAs (Thomas et al., 2014) and Shewanella putrefaciens strain CN32 (Han et al., 2017). In the new pathway, the nitro group in $\operatorname{Rox}(\mathrm{V})$ is first reduced to amino group to form the compound 3-AHPAA(V), and the latter is then acetylated into N-AHPAA(V). N-AHPAA (V) was found to be stable.

\section{CONCLUSIONS}

To our best knowledge, strain CZ-1 is the first aerobic bacterium with a Rox $(\mathrm{V})$-degrading ability isolated from an arsenic-contaminated paddy soil. A novel transformation pathway of $\operatorname{Rox}(\mathrm{V})$ by this strain is proposed.

\section{ACKNOWLEDGEMENTS}

This study was supported by the Natural Science Foundation of China (grant 41703069 and 41330853), the Natural Science Foundation of Jiangsu Province (grant BK 20170723).

\section{REFERENCES}

Chen, G.W., Ke, Z.C., Liang, T.F., Liu, L. \& Wang, G. 2016. Shewanella oneidensis MR-1-induced Fe (III) reduction facilitates roxarsone transformation. PLoS One 11(4): e0154017.

Cortinas, I., Field, J.A., Kopplin, M., Garbarino, J.R., Gandolfi, A.J. \& Sierra-Alvarez, R. 2006. Anaerobic biotransformation of roxarsone and related N-substituted phenylarsonic acids. Environ. Sci. Technol. 40(9): 29512957.

Guzman-Fierro, V.G., Moraga, R., Leon, C.G., Campos, V.L., Smith, C. \& Mondaca, M.A. 2015. Isolation and characterization of an aerobic bacterial consortium able to degrade roxarsone. Int. J. Environ. Sci. Technol. 12(4): 1353-1362.

Han, J.C., Zhang, F., Cheng, L., Mu, Y., Liu, D. F., Li, W. W. \& Yu H.Q. 2017. Rapid release of arsenite from roxarsone bioreduction by exoelectrogenic bacteria. Environ. Sci. Technol. Lett. 4(8): 350-355.

Nachman, K.E., Graham, J.P., Price, L.B. \& Silbergeld, E.K. 2005. Arsenic: a roadblock to potential animal waste management solutions. Environ. Health Perspect. 113(9): 1123-1124.

O’Conner, R., O’Conner, M., Irgolic, K., Sabrsula, J., Gurleyuk, H., Brunette, R., Howard, C., Garcia, J., Brien, J., Brien, J. \& Brien, J. 2005. Transformation, air transport, and human impact of arsenic in poultry litter. Environ. Forensics 6(1): 83-89.

Stolz, J. F., Perera, E., Kilonzo, B., Kail, B., Crable, B., Fisher, E., Ranganathan, M., Wormer, L. \& Basu, P. 2007. Biotransformation of 3-nitro-4-hydroxybenzene arsonic acid (Roxarsone) and release of inorganic arsenic by Clostridium species. Environ. Sci. Technol. 41(3): 818-823.

Thomas, J.A., Chovanec, P., Stolz, J.F. \& Basu, P. 2014. Mapping the protein profile involved in the biotransformation of organoarsenicals using an arsenic metabolizing bacterium. Metallomics 6(10): 1958-1969. 